\title{
Profile and outcome of pediatric intussusception: a 5-year experience in a tertiary care center
}

\author{
Aqeela J. Madan ${ }^{1,2^{*}}$ (D) Fayza Haider ${ }^{2,3}$ and Saeed Alhindi2,3
}

\begin{abstract}
Background: Intussusception is the most frequent cause of bowel obstruction in infants and toddlers; idiopathic intussusception occurs predominantly under the age of 3 and is rare after the age of 6 years; the highest incidence occurs in infants between 4 and 9 months; the gold standard for treatment of intussusception is non-operative reduction. This research will tackle the problem of pediatric intussusception in our center which is the largest tertiary center in our region. The primary outcome is to study the profile of intussusception; the secondary outcome is to assess the success rate of pneumatic reduction in the center's pediatric population as well as to study the seasonal variation if present.

Results: During the study period, eighty-six ( $N=86)$ cases were identified, from which 10 cases were recurrent intussusception. Seventy-six ( $N=76)$ cases were included from the study period. $N=68(89 \%)$ were less than 3 years of age, and only $\mathrm{N}=2$ (3\%) were above 6 years. Seasonal variation was not significant; $\mathrm{N}=69$ (91\%) patients had successful pneumatic reduction under fluoroscopy while thirteen patients $\mathrm{N}=13$ (17\%) needed operative intervention.

Conclusion: lleocolic intussusception is one of the most common pediatric surgical emergencies that can be successfully managed non-operatively in our institute; $89 \%$ of the cases were below 3 years of age, and no seasonal variation was demonstrated. Operative intervention was required in 13 cases with the main reason being lead point. The fact that the pediatric surgeon performs the reduction might have contributed to a high success rate reaching $91 \%$ in our center. This study provides a valuable opportunity for future regional data comparisons and pooled data analyses.
\end{abstract}

Keywords: Intussusception, Pneumatic reduction, Surgical reduction, Lead point

\section{Background}

Intussusception is the most frequent cause of bowel obstruction in infants and toddlers. It is an acquired invagination of the proximal bowel (intussusceptum) into the distal bowel (intussuscipiens). It was first described in 1674 by Paul Barbette of Amsterdam, defined by

\footnotetext{
*Correspondence: Aqeelajmadan@outlook.com

'Department of Surgery-Pediatric Surgery Unit, Salmaniya Medical Complex,

Manama, Bahrain

${ }^{2}$ Salmaniya Medical Complex, Al Salmaniya Area, P.O. Box 12, Manama,

Bahrain

Full list of author information is available at the end of the article
}

Treves in 1899 , and operated on successfully in 1873 by John Hutchinson [1].

Idiopathic intussusception occurs predominantly under the age of 3 and is rare after the age of 6 years. Most patients are well-nourished, healthy infants, and approximately two-thirds are boys. The highest incidence occurs in infants between 4 and 9months, and it is also the most common cause of small bowel obstruction in this age group. Intussusception is uncommon below 3 months and above 3 years of age [2].

This topic is especially important in the pediatric surgery field as it is a primary deferential for all patients in this group that attend the emergency department with

\section{Springer Open}

(c) The Author(s). 2021 Open Access This article is licensed under a Creative Commons Attribution 4.0 International License, which permits use, sharing, adaptation, distribution and reproduction in any medium or format, as long as you give appropriate credit to the original author(s) and the source, provide a link to the Creative Commons licence, and indicate if changes were made. The images or other third party material in this article are included in the article's Creative Commons licence, unless indicated otherwise in a credit line to the material. If material is not included in the article's Creative Commons licence and your intended use is not permitted by statutory regulation or exceeds the permitted use, you will need to obtain permission directly from the copyright holder. To view a copy of this licence, visit http://creativecommons.org/licenses/by/4.0/. 
complaint of abdominal pain or vomiting; the complications are well documented and can be fatal as well.

This research will tackle the problem of pediatric intussusception in our center which is a tertiary health care institute. Our primary outcome is to study the profile of intussusception, and the secondary outcome is to assess the rate of pneumatic reduction in the centers' pediatric population as well as to study the seasonal variation if present.

\section{Methods}

This is a retrospective chart review study. Patients' data were collected from the files and electronic health record of our center from first of May 2015 till the 31st of May 2020. The study subjects included all patients that were diagnosed with intussusception between the neonatal period to 14 years of age, as this is considered as the pediatric age group.

There were no exclusion criteria. All the recurrent cases were counted as one entry. The study design is a retrospective cross-sectional study; the sample size was 86 cases reduced to 76 as 10 cases were recurrent. The sampling technique used was all pediatric patients with intussusception registered in the pediatric ward registry compared with the list from the electronic health records under the ICD10 code (K56.1).

A data collection sheet was constructed on Excel, and a form was made where the data was entered immediately during collection. Basic demographic data including date of birth, gender, age, and diagnosis were added to the excel sheet. More specific data like month of admission, season, symptoms during presentation, radiological findings, type of intussusception, number of reduction attempts, failure of reduction, and surgical outcome if applicable were all entered on the form. IBM SPSS V.26 was used to perform the statistical analysis.

\section{Ethical approval}

This study was conducted in accordance with the principles of Helsinki Declaration. It was ethically approved by the secondary care medical research subcommittee, Ministry of Health, Kingdom of Bahrain.

\section{Results}

During the study period, $\mathrm{N}=86$ cases were identified, of which 10 cases were recurrent. $\mathrm{N}=76$ cases were included from the study period. $\mathrm{N}=68(89 \%)$ were less than 3 years of age, 6 patients (8\%) were between 3 and 6 years, and only 2 patients (3\%) were above 6 years (Fig.1).

$\mathrm{N}=46$ (61\%) of the subjects were male, and $\mathrm{N}=30$ (39\%) were female. $\mathrm{N}=57$ (75\%) were Bahraini, and $\mathrm{N}=$ 13 (25\%) were non-Bahraini; no statistical significance was found in rate of intussusception or failure of reduction according to nationality.

March, May, and August marked the highest rate of admissions of pediatric intussusception at our institute (12\% March and May, 11\% August) (Fig. 2), N=44 (58\%) were admitted in summer, and $\mathrm{N}=32(42 \%)$ were admitted in winter (Table 1). $\mathrm{N}=33(43 \%)$ presented on the first day of symptoms, and $\mathrm{N}=17(22 \%)$ presented on the third day or after (Fig. 3).

The main presenting symptom was inconsolable crying with episodes of drowsiness in between. $\mathrm{N}=73$ (96\%) had confirmed intussusception on ultrasound, 2 patients had ileoileocolic intussusception, and one patient was reported to have jejuno-ileal intussusception, 2 patients had enteric duplication cyst as a lead point that was confirmed by CT scan of the abdomen, one patient had Meckel's diverticulum, and another had intussusception with a mass as a lead point that was confirmed to be a lymphoma later.

$\mathrm{N}=69$ (91\%) patients had successful pneumatic reduction under fluoroscopy; on the other hand, $\mathrm{N}=7$ (9\%) had unsuccessful attempts. $\mathrm{N}=52(68 \%)$ patients had

\section{Age in Years}

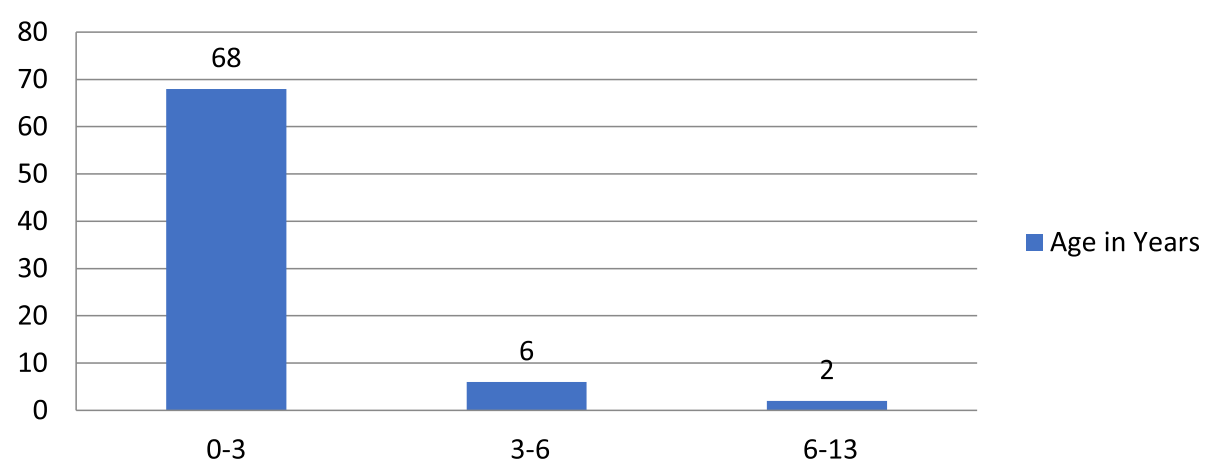

Fig. 1 Number of patients according to age 


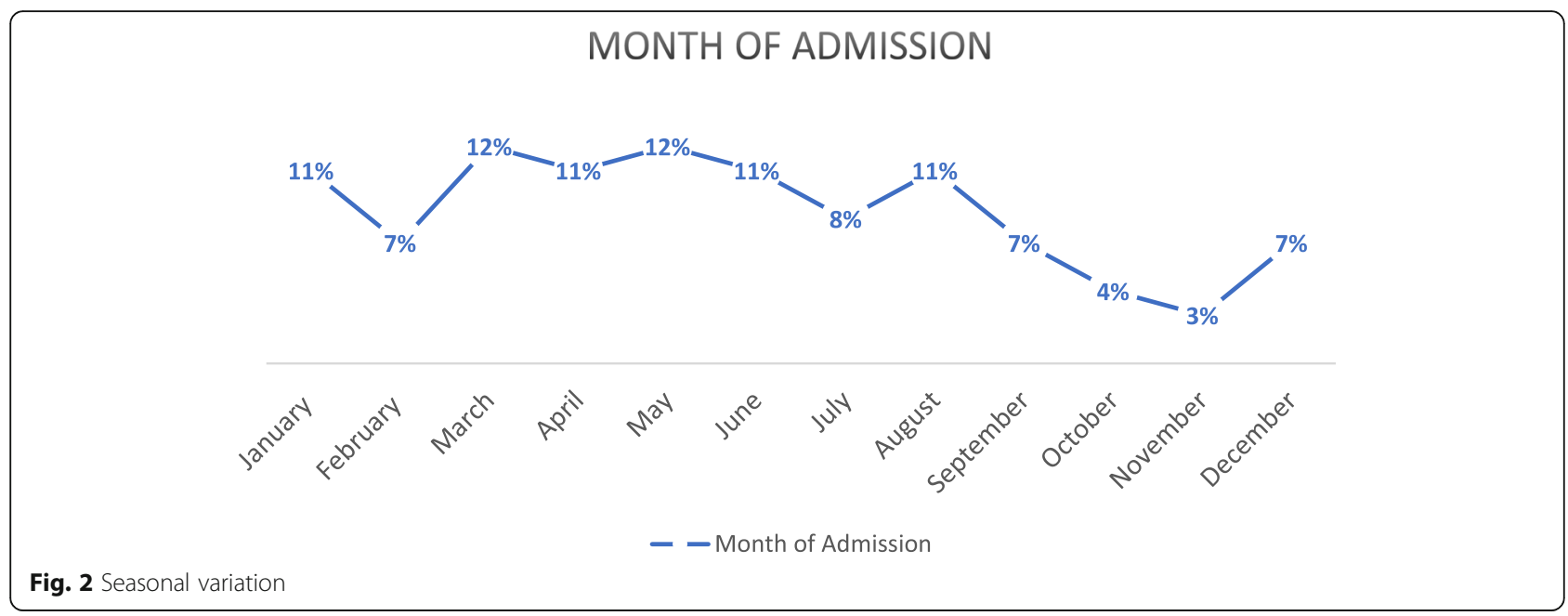

successful reduction from the first attempt whereas $\mathrm{N}=12$ (16\%) needed 3 attempts to achieve reduction (Fig. 4).

$\mathrm{N}=10(13 \%)$ had recurrent intussusception within the same year or same presentation. Thirteen patients needed operative intervention, 3 due to failed reduction and 2 due to a lead point confirmed by CT; another 2 patients were operated due to perforation during reduction and an unfortunate case of a tumor (Burkitt's lymphoma) acting as a lead point in a 9-year-old girl that was excised successfully. One of the patients operated was found to have gangrenous appendicitis and not intussusception. There were no mortalities in this study, and all the subjects recovered well.

\section{Discussion}

This study focuses on intussusception in the largest tertiary care center in our country. The aim of this study is to describe the profile of intussusception in our country including the percentage of cases that required surgery and the indication for the surgical intervention knowing that pneumatic reduction is the gold standard and has a high success rate [3].

The higher incidence of intussusception in our study was in children less than 3 years of age (89\%) which is in the range of the known age for idiopathic intussusception, that is between 6 months and 3 years of age; most of the studies were focused on intussusception in children aged less than 2 years. It has been noticed that the gender of the patients was approximately the same with no statistical difference, and slight male predominance was seen. In our review of the literature, there were no differences between male and female as well [4].

The main nationality of the patients was for sure the Bahraini nationality; however, it was observed that the foreign population had a tendency towards failure of pneumatic reduction mainly due to delayed presentation, but it was not statistically significant [5].

In this study, we tried to identify the seasonal variation in the pattern of admission. It was noticed that the admission rate of intussusception increased in the months of April/May and August/September which can be explained by the period of change in weather in Bahrain as it correlates with the transition between summer and winter. It has been postulated that in this period the rate of viral infections whether upper respiratory or gastrointestinal is higher [6] as it may correlate with the increase in the intussusception suspicion rate and helps in diagnosing more cases of intussusception. There was no statistical difference between the number of patients in both seasons specifically as stated in other countries [7].

Most of our patients presented on the first day of symptoms with the history of inconsolable episodic crying. Not many patients presented with the classical triad of abdominal pain, vomiting, and red currant jelly stools [8] and quite a few presented with a picture of intestinal obstruction due to delayed presentation.

Table 1 Summer vs winter

\begin{tabular}{|c|c|c|c|c|c|c|c|}
\hline & & \multicolumn{4}{|c|}{ U/S findings } & \multirow{2}{*}{\multicolumn{2}{|c|}{ Total }} \\
\hline & & \multicolumn{2}{|c|}{ Other } & \multicolumn{2}{|c|}{ Intussusception } & & \\
\hline & & No. & $\%$ & No. & $\%$ & No. & $\%$ \\
\hline \multirow[t]{2}{*}{ Season of admission } & Winter & 1 & $3.1 \%$ & 31 & $96.9 \%$ & 32 & $100.0 \%$ \\
\hline & Summer & 1 & $2.3 \%$ & 43 & $97.7 \%$ & 44 & $100.0 \%$ \\
\hline \multicolumn{2}{|l|}{ Total } & 2 & $2.6 \%$ & 74 & $97.4 \%$ & 76 & $100.0 \%$ \\
\hline
\end{tabular}



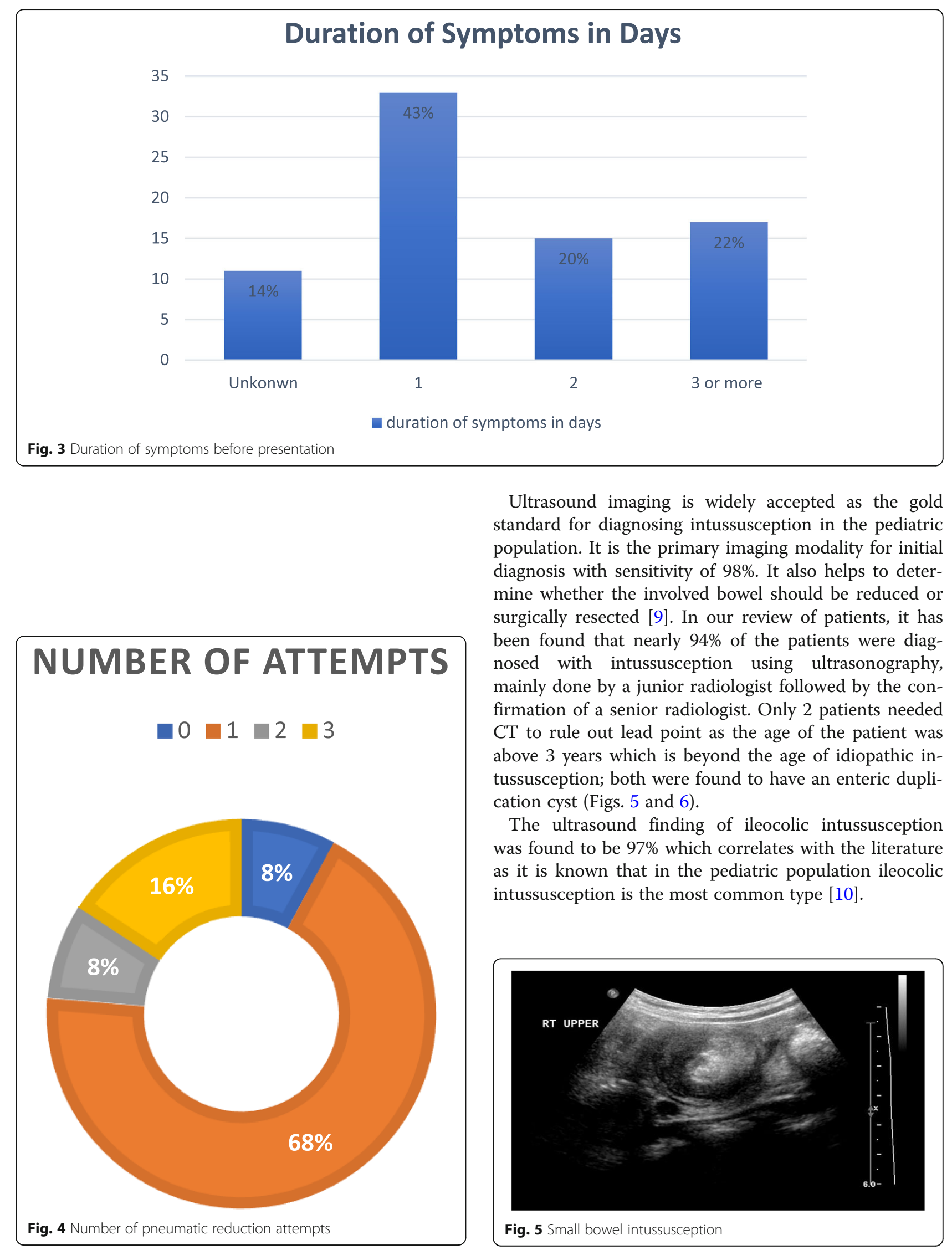

Ultrasound imaging is widely accepted as the gold standard for diagnosing intussusception in the pediatric population. It is the primary imaging modality for initial diagnosis with sensitivity of $98 \%$. It also helps to determine whether the involved bowel should be reduced or surgically resected [9]. In our review of patients, it has been found that nearly $94 \%$ of the patients were diagnosed with intussusception using ultrasonography, mainly done by a junior radiologist followed by the confirmation of a senior radiologist. Only 2 patients needed CT to rule out lead point as the age of the patient was above 3 years which is beyond the age of idiopathic intussusception; both were found to have an enteric duplication cyst (Figs. 5 and 6).

The ultrasound finding of ileocolic intussusception was found to be $97 \%$ which correlates with the literature as it is known that in the pediatric population ileocolic intussusception is the most common type [10].

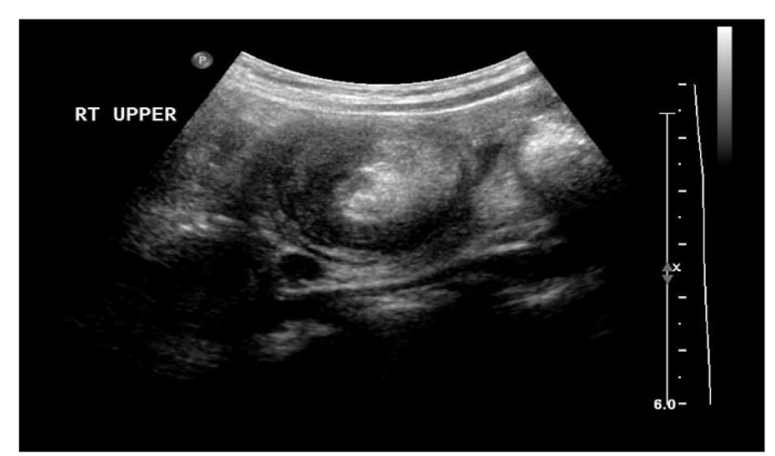

Fig. 5 Small bowel intussusception 


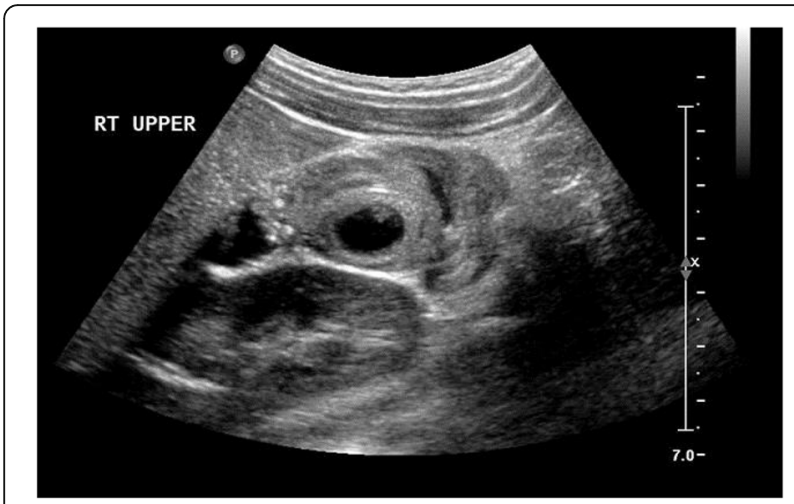

Fig. 6 Small bowel cystic lesion

Regarding the success rate of intussusception in our institute, it has been found to be approximately $91 \%$. In other countries, the success rate of pneumatic reduction was $61 \%$ [11], and in another study, it was reported that successful reduction was achieved in $74 \%$ of the patients [12].

We found that the main possible reason for failure was delayed presentation, and in two cases, the reason for failure was perforation during reduction. In another case, it was reported that the patient had ileoileocolic intussusception where the ileocolic part was successfully reduced; however, the patient remained to have small bowel intussusception.

Successful reduction from the first attempt was nearly $70 \%$ as the radiologists of our department always report the number of attempts done during the procedure. Sixteen percent of the patients needed 3 attempts to achieve a successful pneumatic reduction. Our institute does not practice hydrostatic reduction as it needs to be done by a trained radiologist or pediatric surgeon in both detecting intussusception by ultrasonography and reducing it using hydrostatic method at the same time.

The fact that the pediatric surgeons are the ones performing the reduction in our institute is a possible cause of the high success rate; they tend to go for constant higher pressure and perform more attempts if needed. A rectal tube is inserted into the rectum of the child, fixed with tape to close the buttocks tightly, and under fluoroscopic guidance, air is instilled into the large bowel with sustained pressure not exceeding $120 \mathrm{mmHg}$ till a gush of air is seen in the small bowel. This is a tertiary care center; therefore, an emergency theater and a pediatric surgeon are always available in case of perforation during reduction.

The literature agrees on a maximum of 3 attempts in one setting with a 3-min interval in between each attempt; nevertheless, the maximum number of attempts to be done in a single setting while trying for pneumatic or hydrostatic reduction is decided according to the patient's clinical condition [12].
The recurrence rate was not studied in this paper as the 10 patients that had recurrence in the same admission or within the first year were counted as one patient. Recurrent intussusception is relatively common. Delays in the diagnosis of intussusception and reduction can lead to serious complications, including bowel ischemia, perforation, and peritonitis. However, the early diagnosis and management of recurrent intussusception is challenging to pediatricians, radiologists, and pediatric surgeons. Previous studies have noted that the rate of recurrence of intussusception ranges from 8 to $15 \%$, a possible reason for this difference is the high rate of surgical reduction in their studies [13].

We had several cases that required surgical intervention after unsuccessful pneumatic reduction or after recurrence of intussusception in the same admission due to a lead point diagnosed by CT scan of the abdomen. The success of conservative management however was noticed to be higher, and less rate of operative intervention was needed especially comparing to the late $1980 \mathrm{~s}$ where the surgical intervention was up to $67 \%$ in Bahrain [14].

Pathologic lead points such as a tumor, polyp, or Meckel's diverticulum are more common in neonates and children over 5 years old or in those whose intussusceptions are restricted to the small intestine; $40 \%$ of the lead points in this study were Meckel's diverticulum [15].

\section{Conclusion}

Ileocolic intussusception is one of the most common pediatric surgical emergencies that can be successfully managed non-operatively in our institute, $89 \%$ of the cases were below 3 years of age, and no seasonal variation was demonstrated. Operative intervention was required in 13 cases (17\%) with the main reason being lead point. The fact that the pediatric surgeon performs the reduction might have contributed to a high success rate reaching $91 \%$ in our center. This study provides a valuable opportunity for future regional data comparisons and pooled data analyses.

\section{Abbreviations}

ICD10: International Classification of Diseases 10th edition; CT: Computer tomography

\section{Supplementary Information}

The online version contains supplementary material available at https://doi. org/10.1186/s43159-021-00097-5.

Additional file 1. Incidence of Intussusception: Five-Year Hospital-Based Retrospective Review.

Additional file 2. Intussusception: seven years experience in Bahrain.

Acknowledgements

Not applicable 


\section{Authors' contributions}

AM: collected and analyzed the data, wrote the manuscript; FH: helped in writing and revising the manuscript and figures. SH: advised during writing the manuscript. The authors have read and approved the manuscript.

\section{Funding}

No funding was required.

\section{Availability of data and materials}

The datasets used and analyzed during the current study are available from the corresponding author on reasonable request.

\section{Declarations}

\section{Competing interest}

The authors declare that they have no competing interests.

\section{Ethics approval and consent to participate}

This study was conducted in accordance with the principles of Helsinki Declaration. It was ethically approved by the secondary care medical research subcommittee, SMC, Ministry of Health, Kingdom of Bahrain. Reference number is not available.

\section{Consent for publication}

Informed consent form was not needed as this is retrospective study; institutional ethical clearance was obtained as all the information was passed through the ethical committee; other funding agency was not required.

\section{Author details}

${ }^{1}$ Department of Surgery-Pediatric Surgery Unit, Salmaniya Medical Complex, Manama, Bahrain. ${ }^{2}$ Salmaniya Medical Complex, Al Salmaniya Area, P.O. Box 12, Manama, Bahrain. ${ }^{3}$ Department of Surgery-Pediatric Surgery Unit, Arabian Gulf University, Manama, Bahrain.

Received: 28 January 2021 Accepted: 18 May 2021

Published online: 21 July 2021

\section{References}

1. Hutchinson J. A successful case of abdominal section for intussusception, with remarks on this and other methods of treatment. Medico-Chirurgical Transact. 1874;57:31.

2. Huppertz HI, Soriano-Gabarró M, Grimprel E, Franco E, Mezner Z, Desselberger $U$, et al. Intussusception among young children in Europe. Pediatr Infect Dis J. 2006;25(1):S22-9. https://doi.org/10.1097/01.inf.00001 97713.32880.46.

3. Sanz N, Sanchez M, García JA, Taoubeh K, García C, Rollán V. Intussusception: barium vs. pneumatic reduction. Cirugia Pediatrica. 1996; 9(1):21-4.

4. Elyazeed MP. Incidence of intussusception: five-year hospital-based retrospective review. Bahrain Med Bull. 2010;32(2).

5. Ekenze SO, Mgbor SO. Childhood intussusception: the implications of delayed presentation. Afr J Paediatr Surg. 2011;8(1):15-8. https://doi.org/1 0.4103/0189-6725.78662.

6. Zaraket $\mathrm{H}$, Charide R, Kreidieh K, Dbaibo G, Melhem NM. Update on the epidemiology of rotavirus in the Middle East and North Africa. Vaccine. 2017:35(45):6047-58. https://doi.org/10.1016/.vaccine.2017.09.067.

7. Belachew AG, Tadesse A, Bogale BH. Patterns and seasonal variation of intussusception in children: a retrospective analysis of cases operated in a tertiary hospital in Ethiopia. Ethiop Med J. 2016;14:54(1).

8. Vandertuin L, Vunda A, Gehri M, Sanchez O, Hanquinet S, Gervaix A. Intestinal intussusception in children: truly a classic triad? Revue Medicale Suisse. 2011;7(283):451-5.

9. Dadlani A, Lal S, Shahani B, Ali M. Ultrasonography for the diagnosis of intussusception in children: an experience from Pakistan. Cureus. 2020;12(8).

10. Marsicovetere P, Ivatury SJ, White B, Holubar SD. Intestinal intussusception: etiology, diagnosis, and treatment. Clin Colon Rectal Surg. 2017;30(01):030-9.

11. Khorana J, Singhavejsakul J, Ukarapol N, Laohapensang M, Wakhanrittee J, Patumanond J. Enema reduction of intussusception: the success rate of hydrostatic and pneumatic reduction. Ther Clin Risk Manag. 2015;11:1837.
12. Ito Y, Kusakawa I, Murata Y, Ukiyama E, Kawase H, Kamagata S, et al Japanese guidelines for the management of intussusception in children, 2011. Pediatr Int. 2012;54(6):948-58. https://doi.org/10.1111/j.1442-200X.2 012.03622_1.x.

13. Guo WL, Hu ZC, Tan YL, Sheng M, Wang J. Risk factors for recurrent intussusception in children: a retrospective cohort study. BMJ Open. 2017; 7(11):e018604. https://doi.org/10.1136/bmjopen-2017-018604.

14. Khalil HR. Intussusception: seven years experience in Bahrain. J Bahrain Med Soc. 1990;2(3):123-5.

15. Hsu WL, Lee HC, Yeung CY, Chan WT, Jiang CB, Sheu JC, et al. Recurrent intussusception: when should surgical intervention be performed? Pediatrics Neonatol. 2012;53(5):300-3. https://doi.org/10.1016/j.pedneo.2012.07.004

\section{Publisher's Note}

Springer Nature remains neutral with regard to jurisdictional claims in published maps and institutional affiliations.

\section{Submit your manuscript to a SpringerOpen ${ }^{\circ}$ journal and benefit from:}

- Convenient online submission

- Rigorous peer review

- Open access: articles freely available online

High visibility within the field

- Retaining the copyright to your article

Submit your next manuscript at $\boldsymbol{\nabla}$ springeropen.com 